\title{
Epigallocatechin-3-gallate (EGCG) inhibits the migratory behavior of tumor bronchial epithelial cells
}

\author{
Salma Hazgui ${ }^{1}$, Arnaud Bonnomet ${ }^{1}$, Béatrice Nawrocki-Raby ${ }^{1}$, \\ Magali Milliot ${ }^{1}$, Christine Terryn ${ }^{2}$, Jérôme Cutrona ${ }^{1,2}$, Myriam Polette ${ }^{1,3}$, \\ Philippe Birembaut ${ }^{1,3}$ and Jean-Marie Zahm*1
}

\begin{abstract}
Address: ${ }^{1}$ INSERM, UMRS903, Reims, F-51092 France, ${ }^{2}$ Univ Reims Champagne Ardenne, IFR53, Reims, F-51100 France and ${ }^{3} \mathrm{CHU}$ Reims, Hôpital Maison Blanche, Laboratoire Pol Bouin, Reims, F-51092 France

Email: Salma Hazgui - salma.hazgui@univ-reims.fr; Arnaud Bonnomet - arnaud.bonnomet@univ-reims.fr; Béatrice NawrockiRaby - beatrice.raby@univ-reims.fr; Magali Milliot - magali.milliot@univ-reims.fr; Christine Terryn - christine.terryn@univ-reims.fr; Jérôme Cutrona - jerome.cutrona@univ-reims.fr; Myriam Polette - myriam.polette@univ-reims.fr; Philippe Birembaut - pbirembaut@chureims.fr; Jean-Marie Zahm* - jm.zahm@univ-reims.fr

* Corresponding author
\end{abstract}

Published: 2I April 2008

Respiratory Research 2008, 9:33 doi:10.1 186/1465-9921-9-33

This article is available from: http://respiratory-research.com/content/9/1/33

(c) 2008 Hazgui et al; licensee BioMed Central Ltd.

This is an Open Access article distributed under the terms of the Creative Commons Attribution License (http://creativecommons.org/licenses/by/2.0), which permits unrestricted use, distribution, and reproduction in any medium, provided the original work is properly cited.
Received: 24 July 2007

Accepted: 21 April 2008

\begin{abstract}
Background: Many studies associated the main polyphenolic constituent of green tea, (-)Epigallocatechin-3-gallate (EGCG), with inhibition of cancers, invasion and metastasis. To date, most of the studies have focused on the effect of EGCG on cell proliferation or death. Since cell migration is an important mechanism involved in tumor invasion, the aim of the present work was to target another approach of the therapeutic effect of EGCG, by investigating its effect on the cell migratory behavior.
\end{abstract}

Methods: The effect of EGCG (at concentrations lower than $10 \mu \mathrm{g} / \mathrm{ml}$ ) on the migration speed of invasive cells was assessed by using $2 \mathrm{D}$ and $3 \mathrm{D}$ models of cell culture. We also studied the effects of EGCG on proteinases expression by RT-PCR analysis. By immunocytochemistry, we analyzed alterations of vimentin organization in presence of different concentrations of EGCG.

Results: We observed that EGCG had an inhibitory effect of cell migration in 2D and 3D cell culture models. EGCG also inhibited MMP-2 mRNA and protein expression and altered the intermediate filaments of vimentin.

Conclusion: Taken together, our results demonstrate that EGCG is able to inhibit the migration of bronchial tumor cells and could therefore be an attractive candidate to treat tumor invasion and cell migration.

\section{Background}

Cell migration is a prerequisite for cancer invasion and metastasis. Much of the focus on the therapeutic treatment of cancer has involved compounds that target cell proliferation and subsequent cell death. However, target- ing migration is another approach that has not been extensively pursued but holds promise for alternative means of therapy [1]. 
Tea (Camellia sinensis) is a popular beverage worldwide. ()-Epigallocatechin-3-gallate (EGCG), the main polyphenolic constituent of green tea, has been shown to have association with prevention of cancer development, metastasis, invasion and angiogenesis [2]. To date, most of the studies have focused on the effect of EGCG on cell proliferation or death. EGCG has been shown to induce apoptosis in many human cell lines: human lymphoid leukemia cells [3], prostate cancer cell lines [4], human epidermoid carcinoma A431 cells [5], breast carcinoma MCF-7 cells [6], melanoma cells [7] and pancreatic cancer cells [8]. Previous studies demonstrated that it has a selective apoptotic effect in tumor cells compared with normal cells [9]. This polyphenolic component has also an inhibitory effect on angiogenesis that is an important process in tumor growth [10].

The acquisition of an invasive phenotype by epithelial cells implicates a series of changes altering their differentiation [11]. Components of the extracellular matrix play a fundamental role in the process of tumor invasion. Extensive studies in the last decade have revealed that matrix metalloproteases (MMP) are frequently overexpressed in most forms of human tumor $[12,13]$ and are implicated in the destruction of the extracellular matrix, thus facilitating tumor invasion [14,14,15]. EGCG has inhibitory effects on MMP-2 and MT1-MMP in glioblastoma cells [16], reduces MT1-MMP activity in an invasive human fibrosarcoma cell line [17] and induces repression of MMP-9 expression in lung carcinoma cell invasion [18]. It reduces cancer cell proliferation and migration by a combination with ascorbic acid [19], by reducing VEGF production [20]. EGCG also downregulates ephrin-A1mediated endothelial cell migration [21] and melanoma and pancreatic cancer growth and metastasis [22,23]. Using a wound healing assay, Siddiqui et al [24] demonstrated that co-treatment of prostate carcinoma cells with EGCG and TNF-related apoptosis-inducing ligand led to a decrease in cell migration. However, the studies dealing with cell migration were mostly performed by using in vitro models by which cell migration was evaluated by using the Boyden chamber technique, or referred to qualitative rather than quantitative data. Our aim was to use in vitro models of cell migration and to study the EGCG effects on cell movement by analyzing the dynamic cell behavior of a tumor epithelial bronchial cell line. We used a two-dimensional (2D) model of cell dispersion [25] and a three-dimensional (3D) model of cell migration to mimic conditions similar to those observed in vivo during tumor invasion [26]. In parallel we analyzed the effect of EGCG on protease expression and vimentin organization.

\section{Methods \\ Cell lines}

The BZR human bronchial cell line used in our study [27] was derived from normal human bronchial cells immortalized after transfection with the SV40 large T-antigen gene and infected with the v-Ha-ras oncogene. This cell line displays an invasive potential in vitro and tumorigenicity and metastatic ability in athymic nude mice. Cells were cultured in a $5 \% \mathrm{CO}_{2}$ fully humidified atmosphere at $37^{\circ} \mathrm{C}$ in Dulbecco modified Eagle's medium (DMEM) (Gibco BRL, Grand Island, USA) supplemented with penicillin, streptomycin (Eurobio, les Ulis, France) and 10\% fetal calf serum (Gibco BRL). Human epithelial MCF10A cells were obtained from the American Type culture collection and cultured in HAM F12 and DMEM (1:3 v/v) supplemented with $20 \mu \mathrm{g} / \mathrm{ml}$ of adenine, $5 \mu \mathrm{g} / \mathrm{ml}$ of insulin, $0.5 \mu \mathrm{g} / \mathrm{ml}$ of hydrocortisone, $2 \mathrm{ng} / \mathrm{ml}$ of EGF, $5 \mu \mathrm{g} / \mathrm{ml}$ of transferrin, $1.5 \mathrm{ng} / \mathrm{ml}$ of triiodothyronine and $10 \%$ fetal calf serum. EGCG was purchased from Sigma Aldrich (Saint-Quentin Fallavier, France) and stored at $4^{\circ} \mathrm{C}$.

\section{Effect of EGCG on cell death}

The BZR cell line was plated at $1 \times 10^{5} \mathrm{cells} / \mathrm{ml}$ and after 2 days of culture, the medium was removed from the culture plates and replaced with serum free medium with 5, 10 , or $20 \mu \mathrm{g} / \mathrm{ml}$ of EGCG. After $18 \mathrm{~h}$ of cell interaction with EGCG, the fluorescent probe propidium iodide (Invitrogen, Cergy Pontoise, France), diluted at $20 \mathrm{mM}$ in the culture medium, was used to visualize the cell death. Fluorescent images were recorded using an inverted microscope (Zeiss Axiovert 200, Le Pecq, France). From the fluorescent images, the mean grey level, proportional to the number of dead cells, was measured and reported as cell death index.

\section{D cell Migration Assay}

The BZR cell line was plated at $10^{3}$ cells $/ \mathrm{ml}$ and after 2 days of culture, the medium was removed from the culture plates and replaced with serum free medium with 5 $\mu \mathrm{g} / \mathrm{ml}$ or $7.5 \mu \mathrm{g} / \mathrm{ml}$ of EGCG. Cell migration experiments were performed using an inverted microscope (Axiovert 200, Zeiss, Le Pecq, France) equipped with a small transparent environmental chamber (Climabox, Zeiss) with $5 \% \mathrm{CO} 2$ in air at $37^{\circ} \mathrm{C}$. The microscope was driven by the Metamorph software (Roper Scientific, Evry, France) and images of the cells were recorded every $15 \mathrm{~min}$ for 18 hours with a CCD camera (Coolsnap, Roper Scientific) at $20 \times$ magnification The migration speed of BZR cell line was determined as previously described by Zahm et al [28].

\section{D cell migration assay}

Type I collagen gel was extracted from rat tails according to the method described by Chambard et al [29]. To visualize cells in a 3D model, we have developed a microenvi- 
ronment model that consists of a two-layer type I collagen gel (figure 1). The first collagen gel layer was prepared by mixing $400 \mu \mathrm{l}$ type I collagen at $2 \mathrm{mg} / \mathrm{ml}$ with $150 \mu \mathrm{l}$ RPMI $5 \times, 15 \mu \mathrm{l} \mathrm{NaOH} 1 \mathrm{~N}$ and $100 \mu$ l DMEM with $10 \%$ fetal calf serum. To form the first layer of the microenvironment, $150 \mu \mathrm{l}$ of this mixture was deposited on the membrane of a double compartment chamber (Transwell, Corning, Acton, MA) and polymerized for 30 minutes at $37^{\circ} \mathrm{C}$. A second collagen gel layer was formed by mixing $400 \mu \mathrm{l}$ type I collagen at $2 \mathrm{mg} / \mathrm{ml}$ with $150 \mu \mathrm{l}$ RPMI $5 \times, 15 \mu \mathrm{l} \mathrm{NaOH} 1 \mathrm{~N}, 100 \mu$ l DMEM with $10 \%$ fetal calf serum and BZR cell suspension at $13 \times 10^{4}$ cells $/ \mathrm{ml}$. $150 \mu \mathrm{l}$ of this mixture was added over the first layer and $1.5 \mathrm{ml}$ of DMEM was placed into the basal compartment of the chamber that was thereafter maintained for 24 hours at $37^{\circ} \mathrm{C}$. To test the effect of EGCG, the serum free DMEM medium in the baso-lateral compartment was complemented with EGCG at $5 \mu \mathrm{g} / \mathrm{ml}$ or $7.5 \mu \mathrm{g} / \mathrm{ml}$

\section{D time-lapse videomicroscopy}

Using the same microscope as for the 2D migration assay, image sequences of the cells within the collagen gel were recorded every hour at 110 depth levels $(3 \mu \mathrm{m}$ between each depth level) at $20 \times$ magnification. To quantify cell migration, we performed interactive tracking of cell positions in a four-dimensional dataset, as previously described [26]. Once the coordinates $\left(\mathrm{x}_{\mathrm{i},}, \mathrm{y}_{\mathrm{ij}}, \mathrm{z}_{\mathrm{ij}}, \mathrm{t}_{\mathrm{j}}\right)$ of every cell $i$ at each $j$ time setting are recorded in a data file, all the trajectories are known and parameters can be deduced. We measured the cell trajectory length in the horizontal plane (xy), in the vertical direction (z) and the total length of the trajectory (l). It was also useful to visualize these trajectories in the corresponding $3 \mathrm{D}$ space (X, $\mathrm{Y}, \mathrm{Z})$.

\section{RT-PCR Analysis}

Total RNA extraction from subconfluent BZR cells was performed with the High Pure RNA isolation kit (Roche Diagnostics, Meylan, France). RT-PCR was performed with $4 \mathrm{ng} / \mu \mathrm{l}$ of total RNA using the GeneAmp Thermostable RNA PCR kit (Perkin-Elmer, Foster City, CA) and pairs of primers for human MMP-2, MMP-9, MT1-MMP, u-PA and for $28 \mathrm{~S}$ rRNA (Eurogentec, Seraing, Belgium). Forward and reverse primers for human MMP-2, MMP9, MT1-MMP, u-PA and $28 \mathrm{~S}$ were designed as follows:

MMP-2 primers (forward 5'-GGCTGGTCAGTGGCTTGGGGTA-3', reverse5'-AGATCTTCTTCTTC AAGGACCGGTT-3'),

MMP9 primers (forward 5'-GCGGAGATTGGGAACCAGCTGTA-3', reverse 5'-GACGCGCCTGTGTACACCCAACA-3'),

\section{D culture in a double compartment chamber}

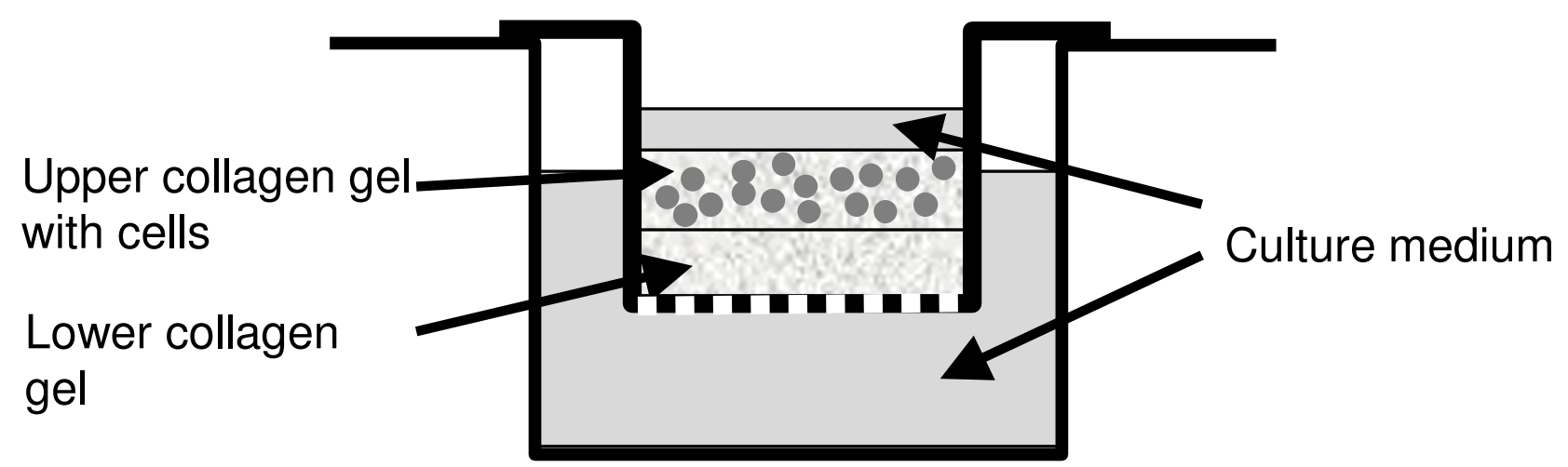

\section{Figure I}

Representation of the 3D culture model. A collagen gel layer was prepared by mixing $400 \mu \mathrm{l}$ type I collagen at $2 \mathrm{mg} / \mathrm{ml}$ with I $50 \mu \mathrm{l}$ RPMI culture medium 5 fold concentrated, I $5 \mu \mathrm{I} \mathrm{NaOH} \mathrm{I} \mathrm{N} \mathrm{and} 100 \mu \mathrm{I}$ DMEM with I0\% fetal calf serum. To form the first layer of the microenvironment, $150 \mu \mathrm{l}$ of this mixture was deposited on the membrane of a double compartment chamber (Transwell) and polymerized for 30 minutes at $37^{\circ} \mathrm{C}$. A second collagen gel layer was formed by mixing $400 \mu \mathrm{l}$ type I collagen at $2 \mathrm{mg} / \mathrm{ml}$ with $150 \mu \mathrm{l}$ RPMI $5 \times, 15 \mu \mathrm{INaH}$ IN, $100 \mu \mathrm{I}$ DMEM with $10 \%$ fetal calf serum and BZR cell suspension at $13 \times 10^{4}$ cells $/ \mathrm{ml}$. I $50 \mu \mathrm{l}$ of this mixture was added over the first layer and $1.5 \mathrm{ml}$ of DMEM was placed into the basal compartment of the chamber which was thereafter maintained for 24 hours at $37^{\circ} \mathrm{C}$. 
MT1-MMP primers (forward 5'-GGATACCCAATGCCCATTGGCCA-3', reverse 5'-CCATTGGGCATCCAGAAGAGAGC-3'),

u-PA primers (forward 5'-CTGTAATACGACTCACTATAGGGGGCACCGG-3', reverse 5'-TCCGGATAGAGATAGTCGGTGTGGTGAGCAAG-3'),

$28 \mathrm{~S}$ primers (forward 5'-GTTCACCCACTAATAGGGAACGTGA-3', reverse 5'-GGATTCTGACTTAGAGGCGTTCAGT-3').

Reverse transcription was performed at $70^{\circ} \mathrm{C}$ for $15 \mathrm{~min}$ utes. Amplification cycles were as follows: 15 seconds at $94^{\circ} \mathrm{C}$, 20 seconds at $68^{\circ} \mathrm{C}$, and 10 seconds at $72^{\circ} \mathrm{C}$. Twenty one cycles were allowed for MMP- 2 amplification, 30 cycles for MMP9 amplification, 20 cycles for MT1MMP amplification, 26 cycles for u-PA amplification, 12 cycles for $28 \mathrm{~S}$ amplification. Products were separated on acrylamide gels, stained with SYBR Gold (Invitrogen, Cergy Pontoise, France), and images were recorded by fluorimetric scanning (LAS-1000, Fuji, Stamford, CT).

\section{Zymography analysis}

The BZR cell line was cultured in 12-well plates $\left(10^{4}\right.$ cells per well). After $48 \mathrm{~h}$ of incubation, the medium was changed to serum-free medium and EGCG was added at different concentrations: 0,5 or $7.5 \mu \mathrm{g} / \mathrm{ml}$. After $18 \mathrm{~h}$ of incubation, the medium conditioned by the BZR was centrifuged. Samples were separated on a $10 \%$ polyacrylamide SDS gel containing $0.1 \%(\mathrm{w} / \mathrm{v})$ gelatine (Sigma Aldrich, Saint-Quentin Fallavier, France). Electrophoresis was carried out at the constant current of $40 \mathrm{~mA}$. The gel was washed for 1 hour at room temperature in a $2 \%(\mathrm{v} / \mathrm{v})$ Triton X-100 solution, transferred to a $50 \mathrm{mmol} / \mathrm{L}$ Tris$\mathrm{HCl} / 10 \mathrm{mmol} / \mathrm{L} \mathrm{CaCl} 2(\mathrm{pH} 7.6)$ buffer and incubated overnight at $37^{\circ} \mathrm{C}$. The gel was stained for 30 minutes in a $0.1 \%(\mathrm{w} / \mathrm{v})$ Coomassie blue (G250)/45\% (v/v) metha$\mathrm{nol} / 10 \%(\mathrm{v} / \mathrm{v})$ acetic acid solution and de-stained in $10 \%$ $(\mathrm{v} / \mathrm{v})$ acetic acid/20\% (v/v) methanol. Proteolytic activity was semi-quantified by densitometric scanning of the bands (LAS-1000, Fuji).

\section{Effect of EGCG on vimentin}

We used the human breast cell line MCF10A in an in vitro model of cell migration. This model consisted in plating 5 $\times 10^{4}$ cells inside a 6 -mm glass ring placed in the middle of a collagen-coated coverslip [30]. Twenty four hours after plating, the glass ring was removed and the cells were covered with growth medium. The cells at the periphery of the culture were left to migrate for $24 \mathrm{~h}$, then they were incubated with EGCG at 0, 5, or $7.5 \mu \mathrm{g} / \mathrm{ml}$ for another 24 $\mathrm{h}$ period. The migratory speeds were measured for $1 \mathrm{~h}$ as previously described and the cells were fixed in cold methanol for $10 \mathrm{~min}$ at $-20^{\circ} \mathrm{C}$. The coverslips were then satu- rated for 30 min with 3\% bovine serum albumin in PBS. After intermediate washes in PBS, monolayers were successively incubated for $1 \mathrm{~h}$ with a monoclonal antibody to vimentin (clone Vim 3B4; Dako, Glostrup, Denmark), with biotinylated sheep anti-mouse antibody and with Alexa Fluor ${ }^{\boxplus} 488$-conjugated streptavidin (Dako). Coverslips were mounted with aqua polymount antifading solution (Polysciences, Warrington, PA) onto glass slides and observed under a fluorescence microscope at $\mathrm{x} 10$ or x63 magnification (AxioImager, Zeiss, Le Pecq, France).

\section{Data analysis}

Values were reported as mean \pm SD from at least 3 different experiments. Student's t-test was used for comparisons between groups and differences were considered to be statistically significant with $P$ values less than 0.05 .

\section{Results \\ Effect of EGCG on cell death}

To visualize the effect of EGCG on cell death, we used the fluorescent probe propidium iodide that specifically tags the nucleus of necrotic cells. Typical images are shown in figure 2. Cells were incubated without EGCG (figure 2A), or with EGCG at $5 \mu \mathrm{g} / \mathrm{ml}$ (figure $2 \mathrm{~B}$ ), $10 \mu \mathrm{g} / \mathrm{ml}$ (figure $2 \mathrm{C}$ ), or $20 \mu \mathrm{g} / \mathrm{ml}$ (figure $2 \mathrm{D}$ ). We observed a dosedependent increase in the number of positive cell nuclei and this increase became significant $(\mathrm{p}<0.01)$ in presence of $20 \mu \mathrm{g} / \mathrm{ml}$ of EGCG (figure 2E).

\section{D analysis of BZR trajectories in relation with cell migration speed}

Observation of time lapse movies built from the phase contrast images recorded every 15 minutes for 18 hours showed an increasing inhibition of BZR migration in parallel with the increase of EGCG concentration. Time-lapse images recorded every 15 min showed that BZR cells in absence of EGCG continuously modified their shape and acquired an elongated morphology corresponding to a migratory phenotype (figure $3 \mathrm{~A}, \mathrm{~B}, \mathrm{C}$ ). At the opposite, the incubation of BZR cells with EGCG at $5 \mu \mathrm{g} / \mathrm{ml}$ (figure $3 \mathrm{D}, \mathrm{E}, \mathrm{F}$ ) or $7.5 \mu \mathrm{g} / \mathrm{ml}$ (figure $3 \mathrm{G}, \mathrm{H}, \mathrm{I}$ ) induced the inhibition of cell shape modifications. From these time-lapse sequences, we quantified the cell migration speed and the results in figure 4 display the cell trajectories computed after 18 hours for the control, (figure 4A), with $5 \mu \mathrm{g} / \mathrm{ml}$ EGCG (figure 4B) and with $7.5 \mu \mathrm{g} / \mathrm{ml}$ EGCG (figure 4C). Quantification of the migration speed showed a significant $(\mathrm{p}<0.01)$ and progressive decrease in presence of EGCG at $5 \mu \mathrm{g} / \mathrm{ml}$ and $7.5 \mu \mathrm{g} / \mathrm{ml}$. This decrease reached $40 \%$ with $5 \mu \mathrm{g} / \mathrm{ml}$ and $68 \%$ with $7.5 \mu \mathrm{g} / \mathrm{ml}$ of EGCG as compared with the control (figure 4D).

\section{D analysis of BZR trajectories}

Videomicroscopy and computational techniques were used to analyze the migratory behavior of cells and the 


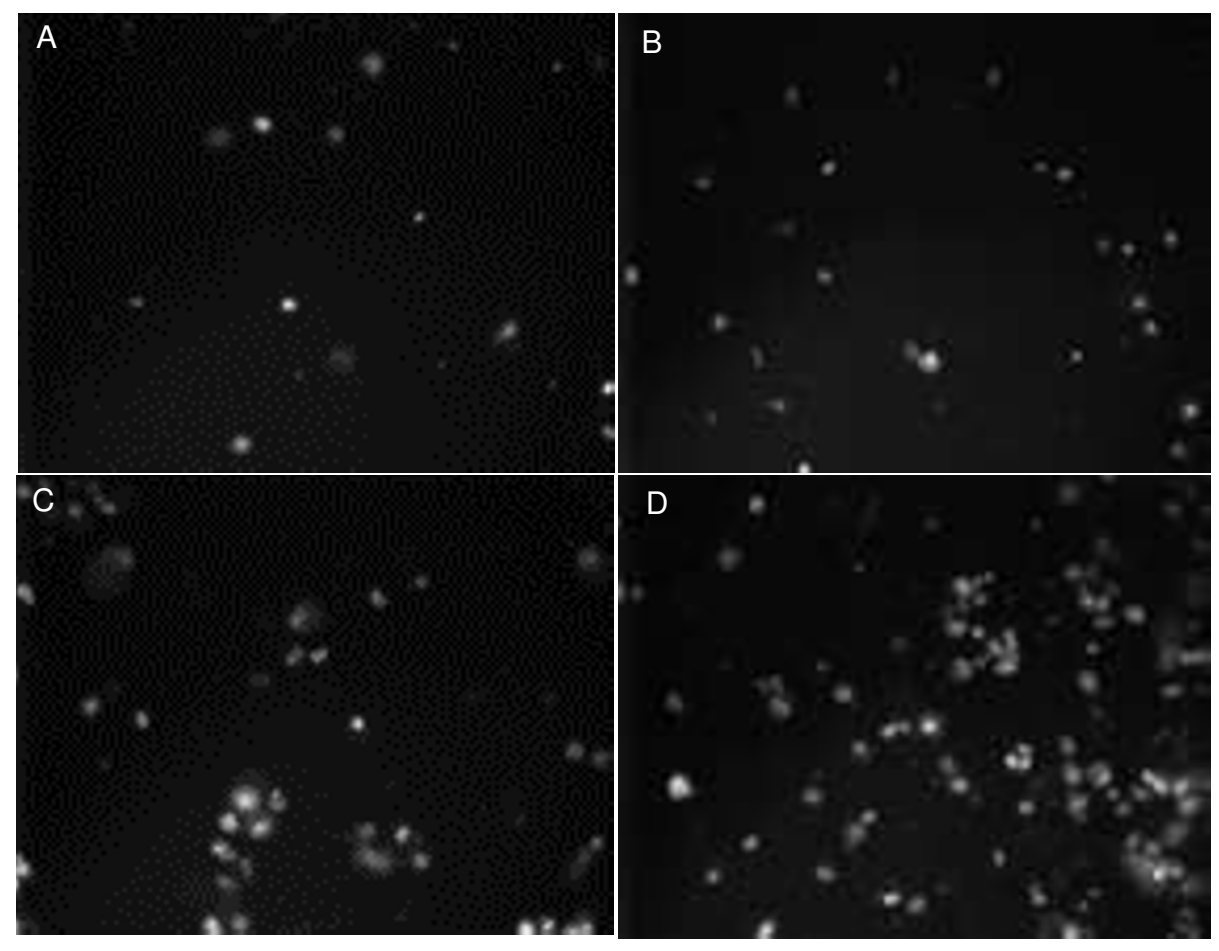

E

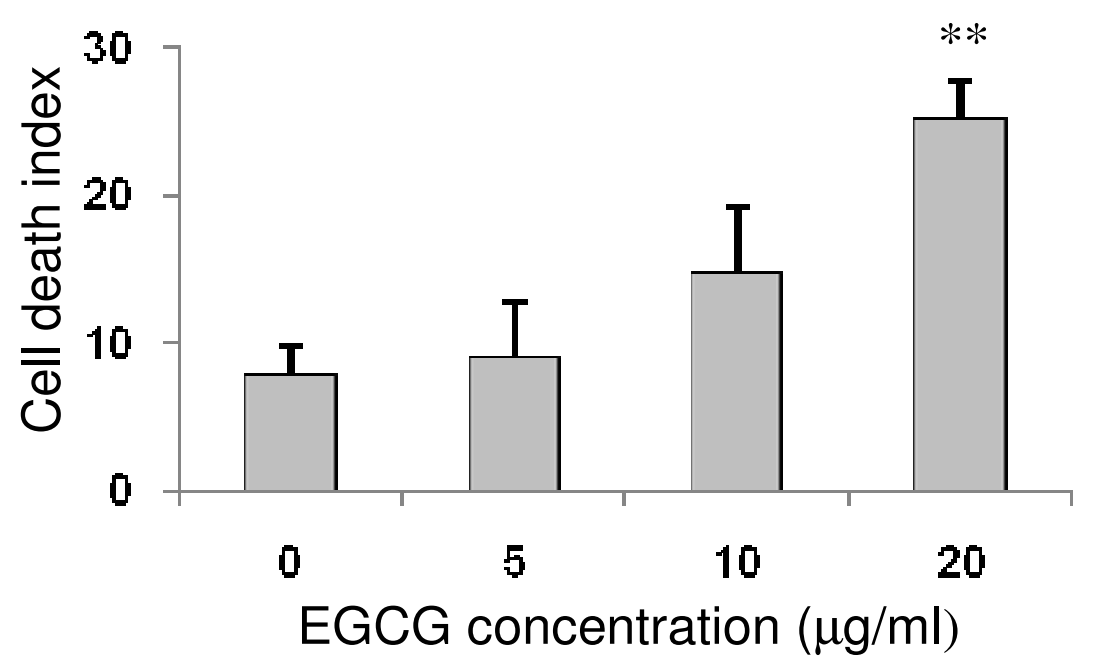

\section{Figure 2}

Effect of EGCG on cell death. Fluorescent images representing the effect of increasing concentrations of EGCG on cell death. The fluorescent probe propidium iodide was used to visualize dead cells. Compared to control $(A)$ or to $5 \mu g / m l(B)$ and $10 \mu \mathrm{g} / \mathrm{ml}(C)$ of EGCG, we observed that $20 \mu \mathrm{g} / \mathrm{ml}(\mathrm{D})$ of EGCG induced a significant $(p<0.0 \mathrm{I})$ increase in the dead cell number $(\mathrm{E})$. 

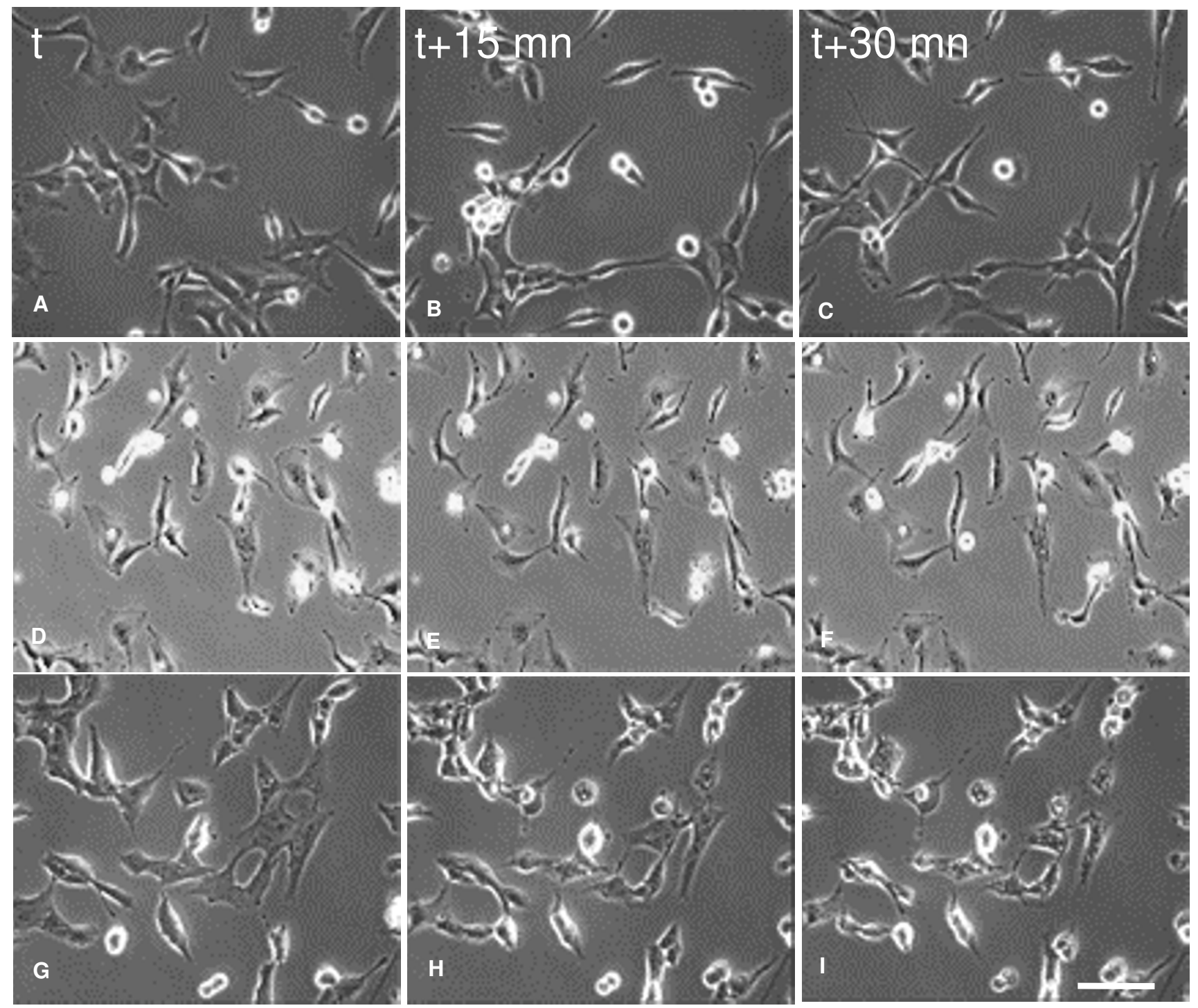

\section{Figure 3}

Phase contrast images of BZR cells. Phase contrast images of BZR cells in control medium or in medium with 5 or $7.5 \mu$ g/ $\mathrm{ml}$ of EGCG. The images were recorded every $15 \mathrm{~min}$. In absence of EGCG, evident alterations of the cell morphology were observed in parallel with the cell displacement $(A, B, C)$. Cell shape modifications and cell movements were less important in presence of $5 \mu \mathrm{g} / \mathrm{ml}$ of EGCG (D, E, F) and were almost completely inhibited in presence of $7.5 \mu \mathrm{g} / \mathrm{ml}$ of EGCG. Scale bar $=50$ $\mu \mathrm{m}$.

effect of EGCG on 3D cell migration. Figure 5A displays the $3 \mathrm{D}$ trajectories of control BZR cells over $18 \mathrm{~h}$ of observation. The trajectories obtained under the same conditions with the BZR cells incubated with $7.5 \mu \mathrm{g} / \mathrm{ml}$ of EGCG are presented in figure $5 \mathrm{~B}$. We observed a higher trajectory length for control BZR cells compared to BZR cells incubated with EGCG. The migration parameters computed from these trajectories are summarized in Figure 5C: a significant decrease $(\mathrm{p}<0.05)$ of the migration speed along the XY horizontal plane was observed for BZR cells in presence of EGCG at $5 \mu \mathrm{g} / \mathrm{ml}$ compared with control BZR cells. When incubated with EGCG at $7.5 \mu \mathrm{g} / \mathrm{ml}$, a significantly $(\mathrm{p}<0.01)$ higher decrease in the migration speed of BZR cells was observed along the XY horizontal plane, the $\mathrm{Z}$ plane and in the XYZ volume, compared with control BZR cells.

\section{RT-PCR and zymography analysis}

To evaluate the effect of EGCG on protease gene expression, we analyzed the mRNA amount of MMP-2, MMP-9, 

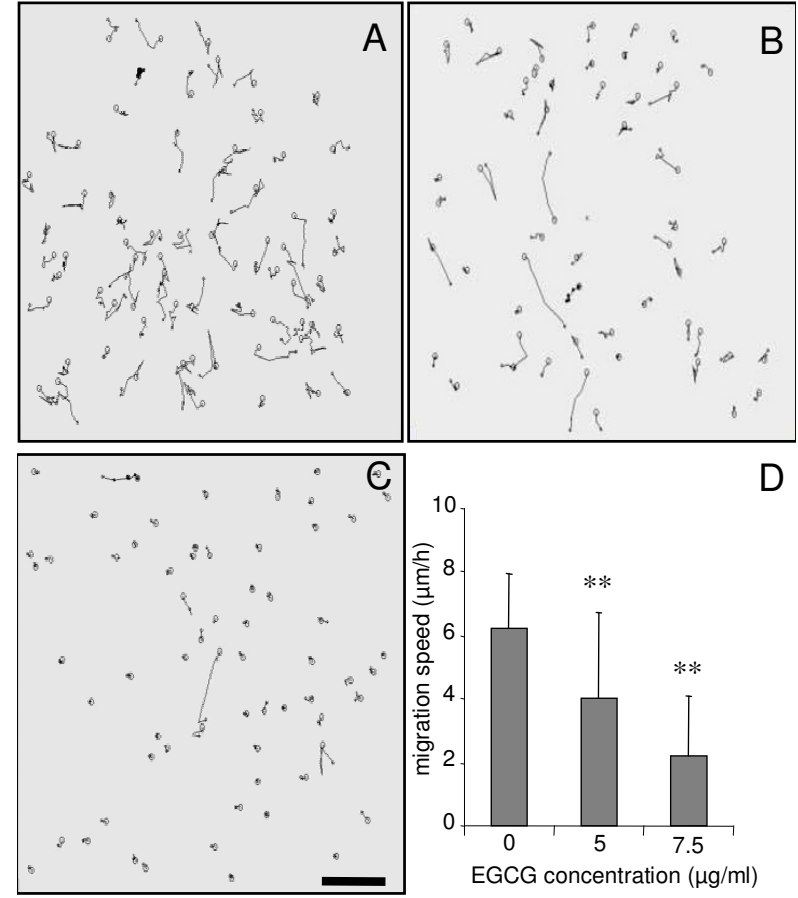

\section{Figure 4}

Two-dimensional representation of the cell trajectories. Trajectories of control BZR cells (A), BZR cells incubated with $5 \mu \mathrm{g} / \mathrm{ml}$ (B) or with $7.5 \mu \mathrm{g} / \mathrm{ml}$ (C) of EGCG for a $18 \mathrm{~h}$ migratory period. A significant $(\mathrm{P}<0.0 \mathrm{l})$ decrease of the migration speed was observed when BZR cells were incubated with increasing concentrations of EGCG, compared with control BZR cells (D). Scale bar $=10 \mu \mathrm{m}$.

MT1-MMP and u-PA using semi-quantitative RT-PCR (figure 6$)$. We observed a significant $(p<0.05)$ decrease of the MMP-2 transcript expression in a dose-dependent manner after $18 \mathrm{~h}$ of treatment with EGCG but we did not observe any significant change of the MT1-MMP and u-PA transcript expression. The level of MMP9 transcript expression was not detectable.

Zymography analysis shows a significant dose-dependent decrease ( $p<0.05)$ of the active and latent form of MMP2 after 18 hours of incubation with EGCG in comparison with the control (Figure 7). No enzymatic activity corresponding to MMP-9 was observed.

\section{Effect of EGCG on vimentin expression}

To examine the potential effect of EGCG on vimentindependent migration, we used the ring culture system that allowed the MCF10A cell line to specifically express vimentin in migratory cells at the periphery of the culture [30]. As shown in figure $8 \mathrm{G}$, we observed that the incubation of migrating MCF10A cells with increasing concentra- tions of EGCG significantly decreased the cell migration speed. In parallel with the decrease in cell migration speed, we noticed different patterns of vimentin expression. In control experiments, most of the cells at the periphery of the ring culture system express vimentin (figure $8 \mathrm{~A}$ ). When the cells were incubated with increasing concentrations of EGCG, the number of cells expressing vimentin progressively decreased (figure $8 \mathrm{~B}, \mathrm{C}$ ). Changes in vimentin organization induced by EGCG are shown in figure 8D, E, F. Untreated Cells were characterized by an homogeneous network of vimentin (figure 8D). Within $18 \mathrm{~h}$ of incubation with $5 \mu \mathrm{g} / \mathrm{ml}$ of EGCG, we observed alterations of the vimentin network that was less expressed and more condensed (figure 8E). In presence of $7.5 \mu \mathrm{g} / \mathrm{ml}$ of EGCG, cell shape changes were observed, in parallel with vimentin disorganization (figure $8 \mathrm{~F}$ ).

\section{Discussion}

Previous studies have shown that EGCG had beneficial effects on cancer prevention and inhibition and that these effects were associated to a large number of mechanisms [10,16,31-33]. In most studies, the concentrations needed to observe these effects typically range from 0.5 to $50 \mu \mathrm{g} /$ $\mathrm{ml}$. EGCG represents approximately $200 \mathrm{mg}$ in a brewed cup of tea, and in mice, for reaching a plasma concentration near to $5 \mu \mathrm{g} / \mathrm{ml}$, the ingestion of $2000 \mathrm{mg} / \mathrm{kg}$ EGCG is necessary. EGCG delivered in the form of capsules (200 $\mathrm{mg}$ ) has been reported to be effective in the patients with human papilloma virus-infected cervical lesions [34]. EGCG has been reported to inhibit cell migration or invasion in liver cancer cells [5], glioblastoma cells [3], vascular smooth muscle cells $[35,36]$, pancreatic stellate cells [37] or during angiogenesis [38]. However, these latter studies were performed by using in vitro models similar to the well-known Boyden chamber assay by which the cell migration was evaluated by counting the number of cells present on the basal side of a porous membrane. To date, the effect of EGCG on the migration speed of tumor cells has not been investigated. We therefore used in vitro models of cell migration associated to computational techniques for studying the effect of EGCG on the migration of invasive cell lines. The effect of EGCG on cell migration was higher when cells were cultured in 2D systems $(65 \%$ decrease in presence of $7.5 \mu \mathrm{g} / \mathrm{ml}$ of EGCG) compared with a $3 \mathrm{D}$ environment $(25 \%$ decrease of the total distance in presence of $7.5 \mu \mathrm{g} / \mathrm{ml}$ of EGCG). This difference in EGCG effect on cell migration speed according to the culture model could be related to the cell-EGCG interaction that could be less effective in the collagen-rich environment used in the 3D culture model. To confirm that the EGCG acted exclusively on cell migration, in preliminary experiments, we also tested the apoptotic effect of EGCG on the BZR cell line and we did not observe significant cell death at EGCG concentrations lower than $10 \mu \mathrm{g} /$ 

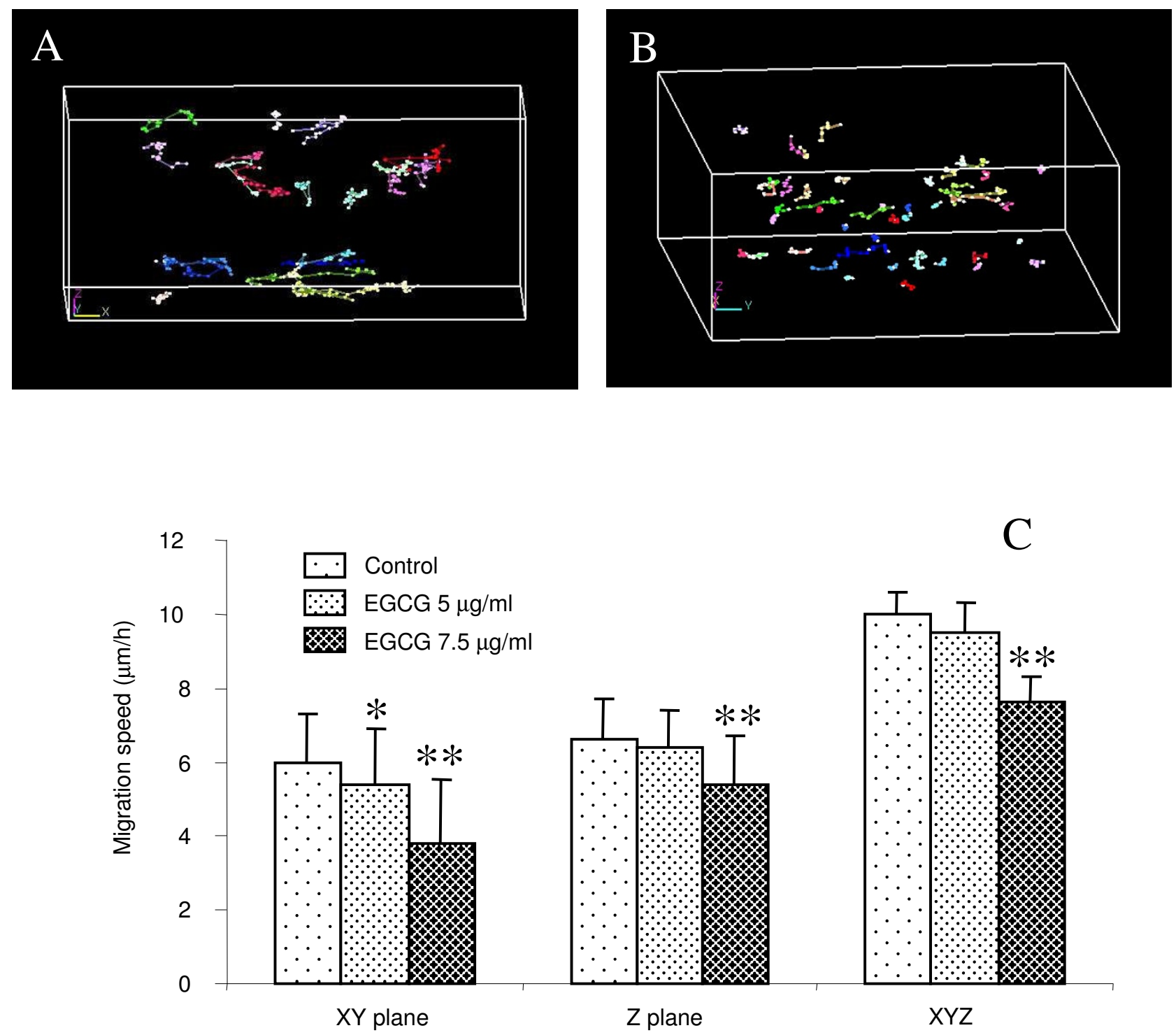

Figure 5

Three-dimensional representation of the cell trajectories. Trajectories of control BZR cells $(A)$ and $B Z R$ cells incubated with $7.5 \mu \mathrm{g} / \mathrm{ml}$ of EGCG (B) for $18 \mathrm{~h}$. Each color on the figure corresponds to different cells. A longer distance of migration was observed for control BZR cells compared with BZR cells treated with EGCG. A significantly lower ( $p<0.05$ ) migration speed along the xy direction was observed for BZR cells in presence of EGCG at $5 \mu \mathrm{g} / \mathrm{ml}$. The presence of EGCG at $7.5 \mu \mathrm{g} / \mathrm{ml}$ in the lower compartment of the cell culture chamber significantly decreased $(p<0.0 \mathrm{I})$ BZR cell migration speed along the $x y, z$ and $x y z$ directions, compared with BZR cell migration speed in absence of EGCG (C).

ml. This emphasizes the inhibitory effect of EGCG on cell migration.

In parallel with the decrease of the migration of cells incubated with EGCG, we observed alterations of the vimentin cytoskeleton network. Vimentin expression has been described in epithelial cells to be involved in pathological or physiological processes that require epithelial cell migration. In addition, data from Gilles et al [39] clearly demonstrated that vimentin expression was related to the migratory status of cells, suggesting that vimentin may play a fundamental role in cell migration. Moreover, vimentin expression was only found in human epithelial tumor cells lines displaying high invasive abilities. The 

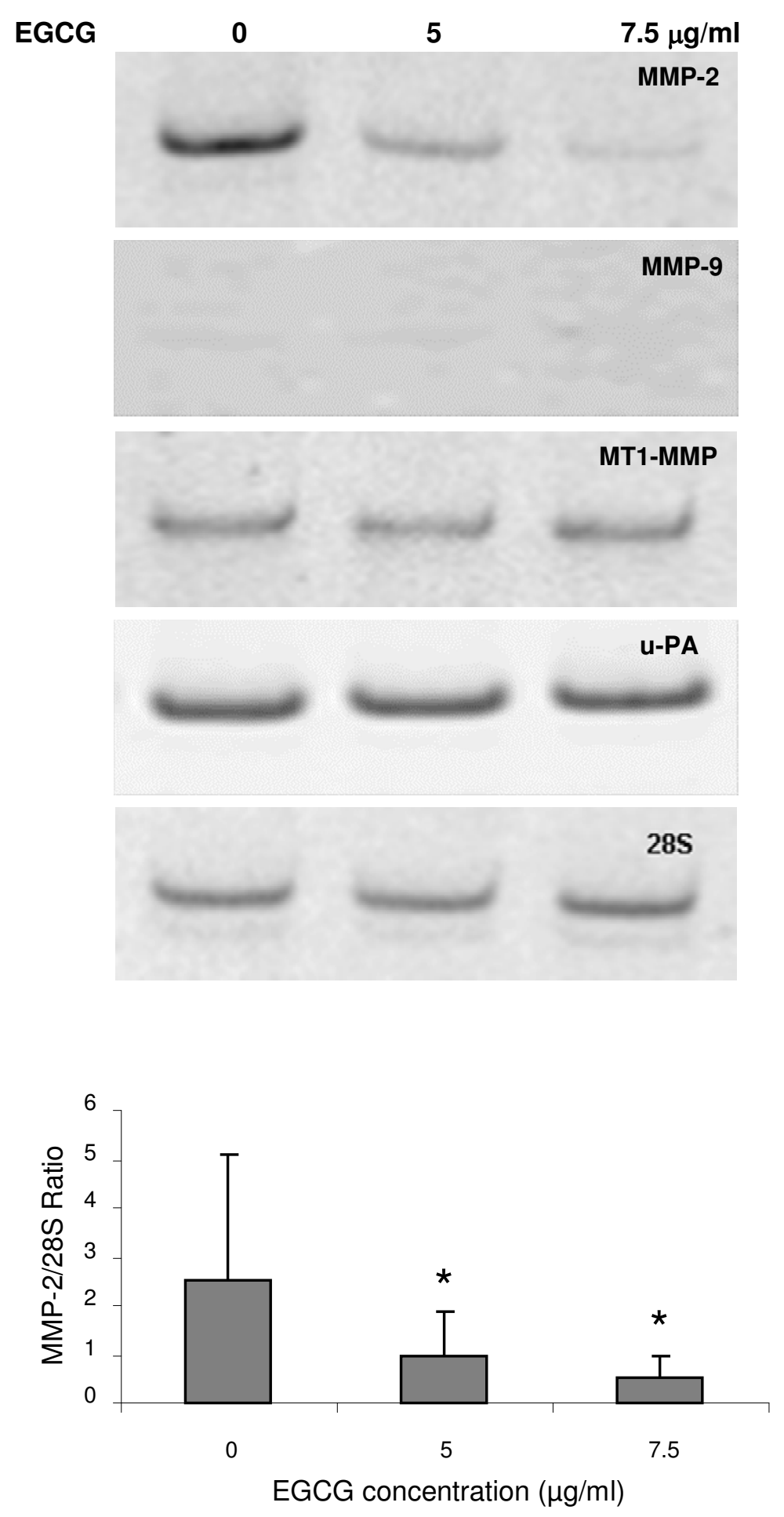

\section{Figure 6}

mRNA expression. mRNA expression for MMP2, MMP9, MTI-MMP and u-PA by BZR cells incubated with increasing concentrations of EGCG. A progressive inhibition of the mRNA level for MMP2 and no changes in MTI-MMP and u-PA mRNA level were observed in parallel with the increase of EGCG concentration. MMP9 expression was not detectable. 

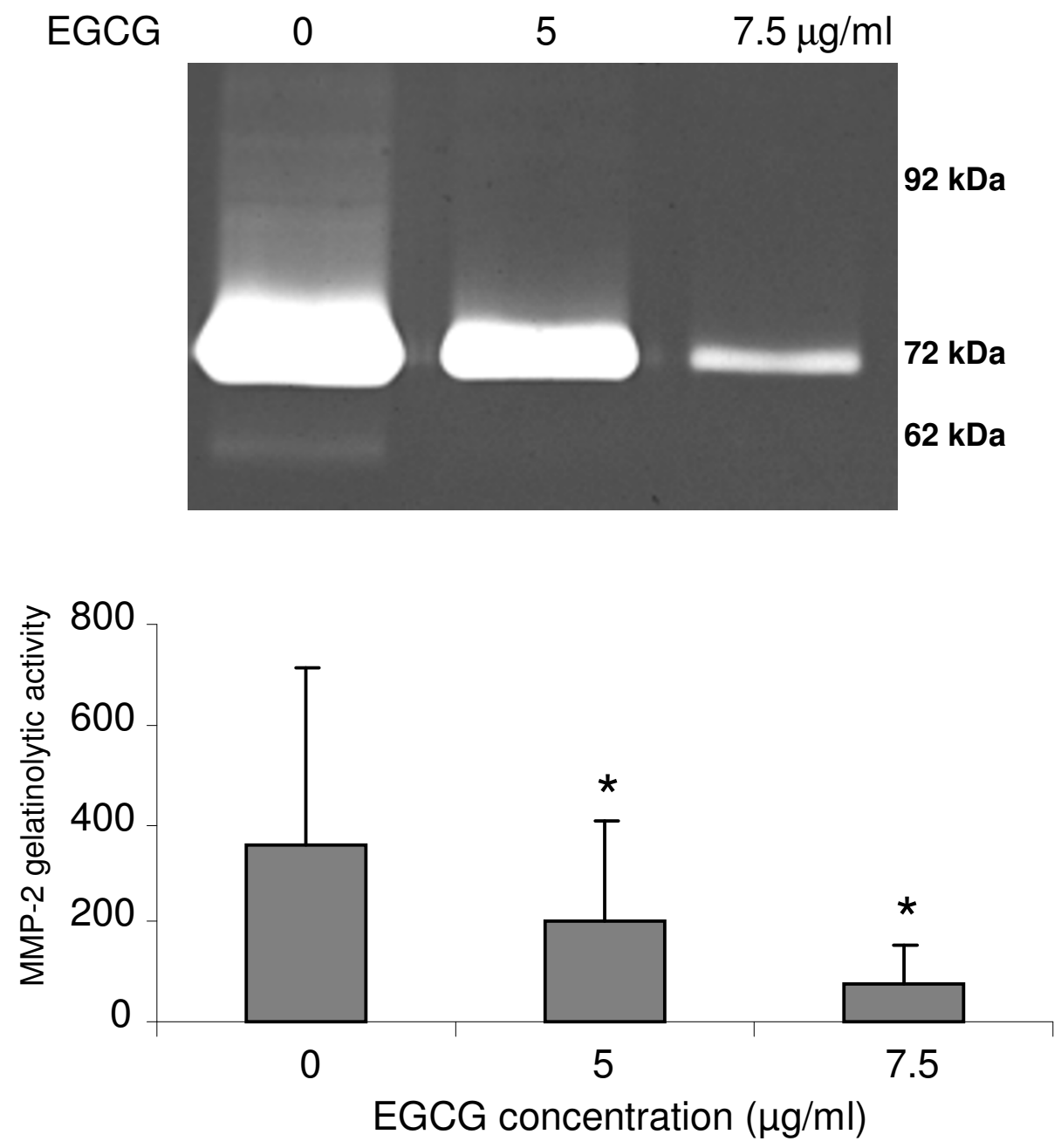

\section{Figure 7}

zymography of the gelatinolytic activities of MMPs. Analysis of the gelatinolytic activities of MMP9 (92 kDa), pro-MMP2 form $(72 \mathrm{kDa})$ and MMP2 active form $(62 \mathrm{kDa})$ of BZR cells incubated with different concentrations of EGCG $(0,5$ and $7.5 \mu \mathrm{g} /$ $\mathrm{ml})$. A significant EGCG dose-dependent decrease $(p<0.05)$ of pro-MMP2 form was observed compared to control. Neither active MMP2 form, nor gelatinolytic activity for MMP9, were observed in presence of EGCG.

BZR cells used in the present study constitutively expresses vimentin independently from their migratory status. To provide a direct link between the inhibitory effect of EGCG on vimentin and migration, we used the MCF10A cell line that has been reported to specifically express vimentin during migration [30]. We observed that the decreased cell migration induced by EGCG was accompanied by a decrease in vimentin expression and organization. We hypothesize that the alterations of the vimentin network induced by EGCG likely led to the decrease of cell migration. Our results are emphasized by those previously reported by Ermakova et al [40] who demonstrated that vimentin is a target for EGCG by inhibiting phosphorylation of vimentin. Although for most motile cells, cell movement is clearly dependent upon the dynamics of an actin microfilament system, intermediate filaments such as vimentin are also important in cell movement because they act to stiffen the internal cytoskeleton and thereby organize actin networks from which filopodia or lamellipodia polymerize outward [41].

Beside the effect of EGCG on vimentin organization, we observed an important inhibition of the expression and the gelatinolytic activity of matrix metalloproteases such as MMP-2 during the incubation with EGCG, but no change was observed concerning MT1-MMP expression. MMP-2 has been shown to be involved in tumor invasion in vitro. Indeed, MMP-2 overexpression has been associated not only with the invasive potential of many tumor cell lines in vitro $[11,27,42]$ but also with the malignant 

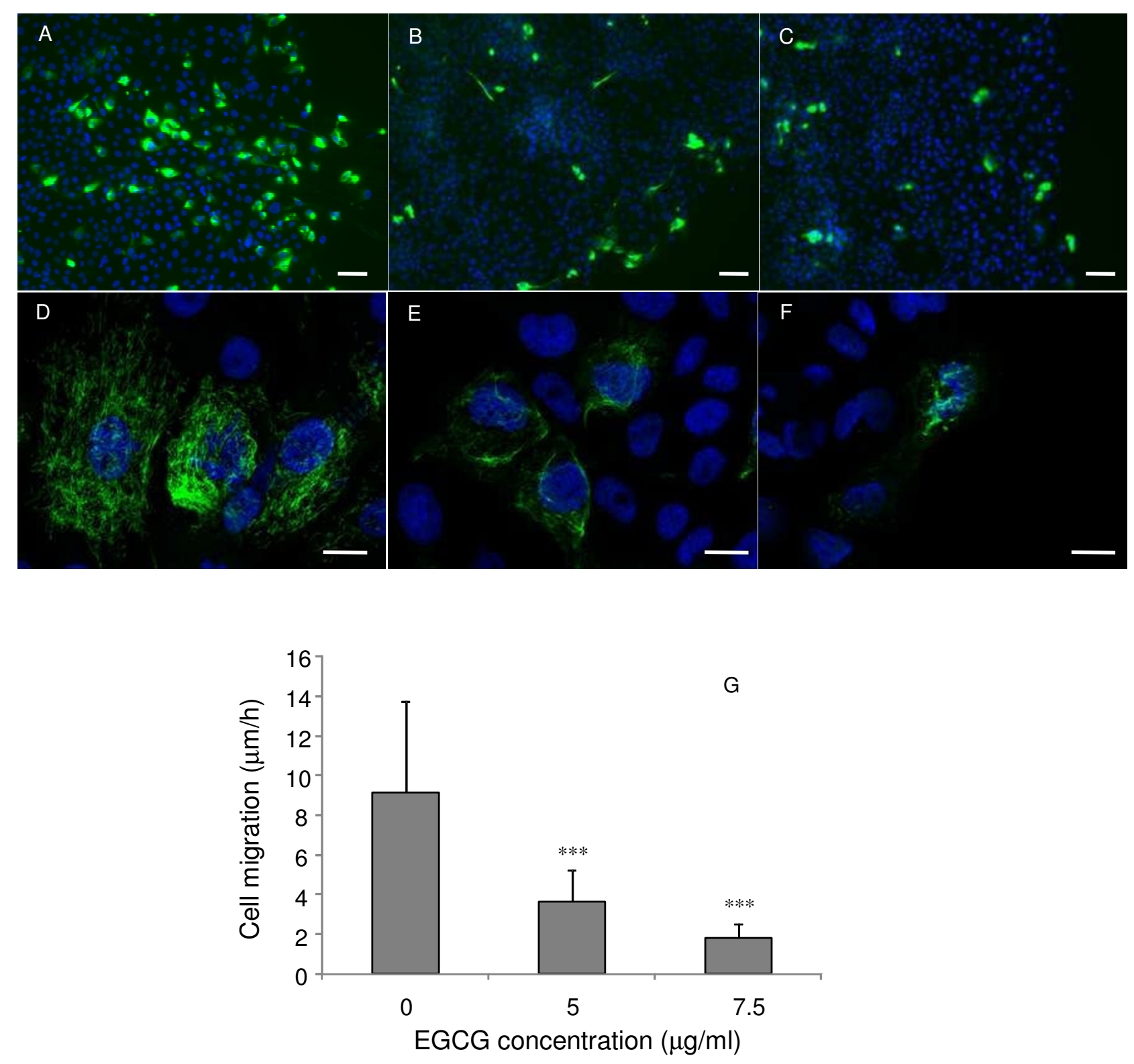

Figure 8

Effect of EGCG on vimentin. Immunolocalization of vimentin in control MCFIOA cells (A, D) or MCFIOA cells incubated with $5(B, E)$ and $7.5 \mu \mathrm{g} / \mathrm{ml}(C, F)$ of EGCG. In presence of EGCG at $5(B)$ or $7.5 \mu \mathrm{g} / \mathrm{ml}(C)$, we observed a decrease in the number of cells expressing vimentin. At higher magnification $(D, E, F)$, alterations of the vimentin network were observed: less expression and more condensed (E, F) compared to control (D). Scale bar $=50 \mu \mathrm{m}(A, B, C)$ or $20 \mu \mathrm{m}(\mathrm{D}, \mathrm{E} F)$.

phenotype in vivo $[43,44]$. Furthermore, many reports have indicated that increased MMP-2 activity was observed in human tumor cell lines displaying an invasive phenotype and was associated with the metastatic potential of breast and colon carcinomas, supporting the essential role of MMP-2 in tumor invasion. We demonstrated, in this study, that EGCG treatment inhibits the activation of MMP-2 associated with a decreased of migratory and invasive capacities of human bronchial tumor cells. We did not observed EGCG-induced variations in MT1-MMP mRNA level. These results are similar to those reported by El Bedoui et al [45] who demonstrated inhibition of MT1MMP activity by green tea extracts rather than changes in MT1-MMP mRNA and protein expression. Accordingly, it has been previously demonstrated that the activity of MT1-MMP and of the active form of MMP-2 in the 
medium of human endothelial cells was decreased in presence of EGCG [46] and that the consequence of the inhibitory activity of metalloproteases was a blocking of tumor cell invasion [2]. EGCG has been shown to affect MMPs both directly and indirectly. Recently, EGCG has been reported to inhibit activating protein-1 (AP-1) that regulates MMP expression. In another way, EGCG could also inhibit the proMMP-2 protein secretion by perturbing the general intracellular vesicular trafficking [16]. A contradictory result is observed for MMP9 which is not expressed under the present experimental conditions, but has been reported in previous experiments [47] to be expressed by BZR cells. This apparent discrepancy in the results could be related to differences in culture conditions. In the present work we used cultures at 50 to $60 \%$ of confluency (which is a necessary condition for accurate measurement of cell migration), whereas the cultures were subconfluent in the previous experiments. In the same manner, we did not detect any variation in u-PA. These results are apparently contradictory with those reported by Jankun et al [48] who noticed an inhibitory effect on u-PA at EGCG concentrations ranging between 1 $\mathrm{mM}$ to $10 \mathrm{mM}$, which are much higher than the concentrations used in the present study (5 to $15 \mu \mathrm{M}$ ).

\section{Conclusion}

Taken together our results demonstrate that beside their well-known antiproliferative effects, green tea catechins are also able to inhibit the migration of bronchial tumor cells and could therefore be attractive candidates to treat tumor invasion.

\section{Competing interests}

The authors declare that they have no competing interest.

\section{Authors' contributions}

SH carried out the BZR cell cultures, videomicroscopic recordings, quantification and drafted the manuscript. $\mathrm{AB}$ performed MCF10 cell cultures and migration experiments. BNR participated in RT-PCR, zymography and helped to draft the manuscript. MM participated in RTPCR and performed immunofluorescence. CT participated in the development of images analysis techniques. JC developed images analysis techniques. MP participated in RT-PCR, zymography and helped to draft the manuscript. PB and JMZ conceived the study, participated in its design, coordination and helped to draft the manuscript. All authors read and approved the final manuscript.

\section{Acknowledgements}

$\mathrm{SH}$ was supported by Association de Recherche contre le Cancer (ARC) and Société de Pneumologie de Langue Française (SPLF). AB was supported by Région Champagne Ardenne and Ligue Contre le Cancer. MM was supported by Institut National du Cancer (INCa).

\section{References}

I. Levin EG: Cancer therapy through control of cell migration. Curr Cancer Drug Targets 2005, 5:505-518.

2. Garbisa S, Sartor L, Biggin S, Salvato B, Benelli R, Albini A: Tumor gelatinases and invasion inhibited by the green tea flavanol epigallocatechin-3-gallate. Cancer 200I, 91:822-832.

3. Hibasami H, Achiwa Y, Fujikawa T, Komiya T: Induction of programmed cell death (apoptosis) in human lymphoid leukemia cells by catechin compounds. Anticancer Res 1996, 16:1943-1946.

4. Paschka AG, Butler R, Young CY: Induction of apoptosis in prostate cancer cell lines by the green tea component, (-)-epigallocatechin-3-gallate. Cancer Lett 1998, I30:1-7.

5. Gupta S, Hastak K, Afaq F, Ahmad N, Mukhtar H: Essential role of caspases in epigallocatechin-3-gallate-mediated inhibition of nuclear factor kappa B and induction of apoptosis. Oncogene 2004, 23:2507-2522.

6. Mittal A, Pate MS, Wylie RC, Tollefsbol TO, Katiyar SK: EGCG down-regulates telomerase in human breast carcinoma MCF-7 cells, leading to suppression of cell viability and induction of apoptosis. Int J Oncol 2004, 24:703-7IO.

7. Nihal M, Ahmad N, Mukhtar H, Wood GS: Anti-proliferative and proapoptotic effects of (-)-epigallocatechin-3-gallate on human melanoma: possible implications for the chemoprevention of melanoma. Int J Cancer 2005, I | 4:5 I3-52I.

8. Qanungo S, Das M, Haldar S, Basu A: Epigallocatechin-3-gallate induces mitochondrial membrane depolarization and caspase-dependent apoptosis in pancreatic cancer cells. Carcinogenesis 2005, 26:958-967.

9. Yang GY, Liao J, Li C, Chung J, Yurkow EJ, Ho CT, Yang CS: Effect of black and green tea polyphenols on c-jun phosphorylation and $H(2) O(2)$ production in transformed and non-transformed human bronchial cell lines: possible mechanisms of cell growth inhibition and apoptosis induction. Carcinogenesis 2000, $21: 2035-2039$.

10. Kojima-Yuasa A, Hua JJ, Kennedy DO, Matsui-Yuasa I: Green tea extract inhibits angiogenesis of human umbilical vein endothelial cells through reduction of expression of VEGF receptors. Life Sci 2003, 73:1299-1313.

II. Polette M, Gilles C, de Bentzmann S, Gruenert D, Tournier JM, Birembaut P: Association of fibroblastoid features with the invasive phenotype in human bronchial cancer cell lines. Clin Exp Metastasis 1998, 16:105-112.

12. Edwards DR, Murphy G: Cancer. Proteases--invasion and more. Nature 1998, 394:527-528.

13. Egeblad M, Werb Z: New functions for the matrix metalloproteinases in cancer progression. Nat Rev Cancer 2002, 2:161-174.

14. Yamamura T, Nakanishi K, Hiroi S, Kumaki F, Sato H, Aida S, Kawai $\mathrm{T}$ : Expression of membrane-type-I-matrix metalloproteinase and metalloproteinase- 2 in nonsmall cell lung carcinomas. Lung Cancer 2002, 35:249-255.

15. Liotta LA, Stetler-Stevenson WG: Tumor invasion and metastasis: an imbalance of positive and negative regulation. Cancer Res 1991, 5 I:5054s-5059s.

16. Annabi B, Lachambre MP, Bousquet-Gagnon N, Page M, Gingras D, Beliveau R: Green tea polyphenol (-)-epigallocatechin 3-gallate inhibits MMP-2 secretion and MTI-MMP-driven migration in glioblastoma cells. Biochim Biophys Acta 2002, I542:209-220.

17. Dell'Aica I, Dona M, Sartor L, Pezzato E, Garbisa S: (-)Epigallocatechin-3-gallate directly inhibits MTI-MMP activity, leading to accumulation of nonactivated MMP-2 at the cell surface. $L a b$ Invest 2002, 82:1685-1693.

18. Yang J, Wei D, Liu J: Repressions of MMP-9 expression and NFkappa $B$ localization are involved in inhibition of lung carcinoma 95-D cell invasion by (-)-epigallocatechin-3-gallate. Biomed Pharmacother 2005, 59:98-103.

19. Wei DZ, Yang JY, Liu JW, Tong WY: Inhibition of liver cancer cell proliferation and migration by a combination of (-)-epigallocatechin-3-gallate and ascorbic acid. J Chemother 2003, I 5:59|-595.

20. Zhu BH, Zhan WH, Li ZR, Wang Z, He YL, Peng JS, Cai SR, Ma JP, Zhang $\mathrm{CH}$ : (-)-Epigallocatechin-3-gallate inhibits growth of gastric cancer by reducing VEGF production and angiogenesis. World J Gastroenterol 2007, I 3: I I62-1 I69. 
21. Tang FY, Chiang EP, Shih C): Green tea catechin inhibits ephrinAl-mediated cell migration and angiogenesis of human umbilical vein endothelial cells. J Nutr Biochem 2007, I 8:391-399.

22. Liu JD, Chen SH, Lin CL, Tsai SH, Liang YC: Inhibition of melanoma growth and metastasis by combination with (-)epigallocatechin-3-gallate and dacarbazine in mice. J Cell Biochem 200I, 83:63I-642

23. Shankar S, Ganapathy S, Hingorani SR, Srivastava RK: EGCG inhibits growth, invasion, angiogenesis and metastasis of pancreatic cancer. Front Biosci 2008, I 3:440-452.

24. Siddiqui IA, Malik A, Adhami VM, Asim M, Hafeez BB, Sarfaraz S, Mukhtar $\mathrm{H}$ : Green tea polyphenol EGCG sensitizes human prostate carcinoma LNCaP cells to TRAIL-mediated apoptosis and synergistically inhibits biomarkers associated with angiogenesis and metastasis. Oncogene 2007.

25. Nawrocki RB, Polette M, Gilles C, Clavel C, Strumane K, Matos M, Zahm JM, Van Roy F, Bonnet N, Birembaut P: Quantitative cell dispersion analysis: new test to measure tumor cell aggressiveness. Int J Cancer 200I, 93:644-652.

26. Hazgui S, Bonnet N, Cutrona J, Nawrocki-Raby B, Polette $M$, Chouchane L, Birembaut P, Zahm JM: 3D culture model and computer-assisted videomicroscopy to analyze migratory behavior of noninvasive and invasive bronchial epithelial cells. Am J Physiol Cell Physiol 2005, 289:CI547-CI552.

27. Ura H, Bonfil RD, Reich R, Reddel R, Pfeifer A, Harris CC, KleinSzanto AJ: Expression of type IV collagenase and procollagen genes and its correlation with the tumorigenic, invasive, and metastatic abilities of oncogene-transformed human bronchial epithelial cells. Cancer Res 1989, 49:46 I5-462I.

28. Zahm JM, Kaplan H, Herard AL, Doriot F, Pierrot D, Somelette P, Puchelle $\mathrm{E}$ : Cell migration and proliferation during the in vitro wound repair of the respiratory epithelium. Cell Motil Cytoskeleton 1997, 37:33-43.

29. Chambard M, Gabrion J, Mauchamp J: Influence of collagen gel on the orientation of epithelial cell polarity: follicle formation from isolated thyroid cells and from preformed monolayers. J Cell Biol I98I, 91:157-I66.

30. Gilles C, Polette M, Zahm JM, Tournier JM, Volders L, Foidart JM, Birembaut $P$ : Vimentin contributes to human mammary epithelial cell migration. J Cell Sci 1999, I I 2 ( Pt 24):46 I5-4625.

31. Borska S, Gebarowska E, Wysocka T, Drag-Zalesinska M, Zabel M: Induction of apoptosis by EGCG in selected tumour cell lines in vitro. Folia Histochem Cytobiol 2003, 41:229-232.

32. Lee YK, Bone ND, Strege AK, Shanafelt TD, Jelinek DF, Kay NE: VEGF receptor phosphorylation status and apoptosis is modulated by a green tea component, epigallocatechin-3gallate (EGCG), in B-cell chronic lymphocytic leukemia. Blood 2004, 104:788-794.

33. Yokoyama M, Noguchi M, Nakao Y, Pater A, Iwasaka T: The tea polyphenol, (-)-epigallocatechin gallate effects on growth, apoptosis, and telomerase activity in cervical cell lines. Gynecol Oncol 2004, 92: 197-204.

34. Ahn WS, Yoo J, Huh SW, Kim CK, Lee JM, Namkoong SE, Bae SM, Lee IP: Protective effects of green tea extracts (polyphenon $E$ and EGCG) on human cervical lesions. Eur J Cancer Prev 2003, 1 2:383-390.

35. Cheng XW, Kuzuya M, Nakamura K, Liu Z, Di Q, Hasegawa J, Iwata $M$, Murohara T, Yokota M, lguchi A: Mechanisms of the inhibitory effect of epigallocatechin-3-gallate on cultured human vascular smooth muscle cell invasion. Arterioscler Thromb Vasc Biol 2005, 25:1864-1870.

36. Maeda K, Kuzuya M, Cheng XW, Asai T, Kanda S, Tamaya-Mori N, Sasaki T, Shibata T, Iguchi A: Green tea catechins inhibit the cultured smooth muscle cell invasion through the basement barrier. Atherosclerosis 2003, 166:23-30.

37. Masamune A, Kikuta K, Satoh M, Suzuki N, Shimosegawa T: Green tea polyphenol epigallocatechin-3-gallate blocks PDGFinduced proliferation and migration of rat pancreatic stellate cells. World J Gastroenterol 2005, I I:3368-3374.

38. Tang FY, Nguyen N, Meydani M: Green tea catechins inhibit VEGF-induced angiogenesis in vitro through suppression of VE-cadherin phosphorylation and inactivation of Akt molecule. Int J Cancer 2003, 106:87I-878.

39. Gilles C, Polette M, Piette J, Birembaut P, Foidart JM: Epithelial-tomesenchymal transition in HPV-33-transfected cervical keratinocytes is associated with increased invasiveness and expression of gelatinase A. Int J Cancer 1994, 59:66I-666.

40. Ermakova S, Choi BY, Choi HS, Kang BS, Bode AM, Dong Z: The intermediate filament protein vimentin is a new target for epigallocatechin gallate. J Biol Chem 2005, 280: 16882-16890.

4I. Eckes B, Dogic D, Colucci-Guyon E, Wang N, Maniotis A, Ingber D, Merckling A, Langa F, Aumailley M, Delouvee A, Koteliansky V, Babinet $C$, Krieg T: Impaired mechanical stability, migration and contractile capacity in vimentin-deficient fibroblasts. J Cell Sci 1998, II I ( Pt |3): 1897-1907.

42. Gilles C, Polette M, Seiki M, Birembaut P, Thompson EW: Implication of collagen type I-induced membrane-type I-matrix metalloproteinase expression and matrix metalloproteinase-2 activation in the metastatic progression of breast carcinoma. Lab Invest 1997, 76:65 I-660.

43. Curran S, Murray Gl: Matrix metalloproteinases in tumour invasion and metastasis. / Pathol 1999, 189:300-308.

44. Nawrocki B, Polette M, Marchand V, Monteau M, Gillery P, Tournier JM, Birembaut P: Expression of matrix metalloproteinases and their inhibitors in human bronchopulmonary carcinomas: quantificative and morphological analyses. Int J Cancer 1997, 72:556-564

45. El Bedoui J, Oak MH, Anglard P, Schini-Kerth VB: Catechins prevent vascular smooth muscle cell invasion by inhibiting MTIMMP activity and MMP-2 expression. Cardiovasc Res 2005, 67:317-325.

46. Oku N, Matsukawa M, Yamakawa S, Asai T, Yahara S, Hashimoto F, Akizawa T: Inhibitory effect of green tea polyphenols on membrane-type I matrix metalloproteinase, MTI-MMP. Biol Pharm Bull 2003, 26:1235-1238.

47. Nawrocki-Raby B, Gilles C, Polette M, Martinella-Catusse C, Bonnet N, Puchelle E, Foidart JM, Van Roy F, Birembaut P: E-Cadherin mediates MMP down-regulation in highly invasive bronchial tumor cells. Am J Pathol 2003, 163:653-66I.

48. Jankun J, Selman SH, Swiercz R, Skrzypczak-Jankun E: Why drinking green tea could prevent cancer. Nature 1997, 387:56।.

Publish with Bio Med Central and every scientist can read your work free of charge

"BioMed Central will be the most significant development for disseminating the results of biomedical research in our lifetime. "

Sir Paul Nurse, Cancer Research UK

Your research papers will be:

- available free of charge to the entire biomedical community

- peer reviewed and published immediately upon acceptance

- cited in PubMed and archived on PubMed Central

- yours - you keep the copyright
BioMedcentral 